\section{Rate of simple motor responding as a function of coaction, competition, and sex of the participants ${ }^{1}$}

\author{
D. W. CARMENT, McMaster Iniversity, \\ Hamilton, Ont., Canada
}

Male and female Ss performed a simple motor task, half alone and half coacting. Half of these groups also were given instructions to increase competitive motivation. The dependent variable was their rate of responding. It was found that the presence of a coactor greatly increased the response rate of females but had little effect on males. For both sexes, competition increased the rate of responding only when a coactor was present.

A number of experiments (reviewed by Zajonc, 1965, 1966) have shown, for a variety of species, that the presence of others facilitates performance. Other studies have demonstrated that competition has the same overt effect (Allport, 1924; Church, 1962; Church, Millward, \& Miller, 1963).

The possible interaction between coaction and competition has not been extensively explored. Some time ago, Dashiell (1935) suggested that the effects of these two factors are additive, contributing together to the Ss' level of performance, while Cottrell (1968) has argued that without competition coaction effects will not appear.

The experiment reported here was designed to assess increments in performance attributable to the presence of a coactor as well as increments that could be assigned to competitive motivation. In addition, Ss were separated according to sex. Surprisingly, sex of the Ss has not been taken into consideration in coaction research. It seems reasonable to expect, given North American socialization practices, that females might perform quite differently from males under conditions of coaction and competition. At least two reasons can be suggested to account for possible differences. First, that females are more "socially sensitive [Crown \& Marlow, 1964]" and, secondly, that they are less competitive than males (Uesugi \& Vinacke, 1963).

In the present study, males and females performed a very simple task, some alone and some with a coactor of the same sex. Half of the participants were given instructions designed to enhance the competitive characteristics of the situation. in a moment."

\section{SUBJECTS AND DESIGN}

There were $80 \mathrm{Ss}, 40$ males and 40 females, chosen at random from an introductory psychology course. Within each of these sets, $10 \mathrm{Ss}$ were assigned randomly to each of four conditions: noncompetitive alone (NCA), noncompetitive together (NCT), competitive alone (CA), and competitive together (CT).

\section{APPARATUS AND PROCEDURE}

The apparatus used was a modified Gerbrands-Lindsey conditioning panel connected to standard programming and timing units in an adjoining room. Briefly, the panel consists of two levers that can be pulled out and that are returned by an adjustable tension spring to their original position. Below each lever was a chute for the delivery of reinforcements and above each lever a counter was placed that accumulated the number of reinforcements each $S$ obtained. The reinforcements, in this case ball bearings, were placed by the $S$ in transparent tubes beside the plungers as they were received. Thus, in the two-person situation, each $S$ was aware, visually and numerically, of the number of reinforcements both he and the other had received.

Reinforcements were delivered on a VR-15 schedule. This schedule was chosen on the basis of pilot data which had indicated that it generated response rates that allowed for both decrements and increments in performance to appear.

The Ss were brought to the experimental room and those in the NCA condition were seated before the panel and then instructed: "This experiment is concerned with some aspects of coordination. All you have to do is pull the lever out like this and release it. You can pull it out as fast or as slow as you like, as long as you don't hold it out. A ball bearing will drop down here whenever you are correct. When one drops down pick it up right away and put it in the inside tube here. This will help keep track of how many you've made. When one tube gets full, start on the next one. Any questions? .... Fine. Start to work when these lights come on and stop when the lights go off. O.K. The lights will come on

The following instructions were added for those in the NCT condition: "One last thing, there is no connection between the two sides of this panel. What one of you does, doesn't affect the other. We are simply running two people at a time to get through the experiment faster. Please don't talk to each other while you are working."

The Ss in the competitive conditions, before being seated at the panel, were told: "This experiment is concerned with some aspects of coordination. We are going to ask you to carry out a task which involves pulling a lever. Each time you do it correctly you will receive a ball bearing. In order to make it worthwhile for you, the number of ball bearings you make will be recorded at the end of the session and this will be judged against the numbers all the other participants in the experiment make. If you make more ball bearings than the others you will be given one of these articles over here. Before we explain in more detail would you please fill out this form so that we will know which article you would most like to obtain .... Fine. Thank you." The $S$ ranked the articles in order of preference. The remainder of the instructions were the same as those given in the NCA and NCT conditions.

A session lasted $5 \mathrm{~min}$. The dependent variable was the number of responses (lever pulls) made each minute.

\section{RESULTS}

The data were subjected to an analysis of variance with three between factors (coaction, competition, and sex) and one within factor (time).

The analysis showed a significant main effect of sex of $S(F=5.66, d f=1 / 72$, $p<.05$ ), reflecting a greater overall number of responses made by males. There also was a significant main effect of coaction $(F=23.12, \mathrm{df}=1 / 72, \mathrm{p}<.001)$, indicating that $S s$ performing together made substantially more responses than those in the alone condition. However, a Sex of $S$ by Coaction interaction $(F=5.47$, $\mathrm{df}=1 / 72, \mathrm{p}<.05)$ indicates that males

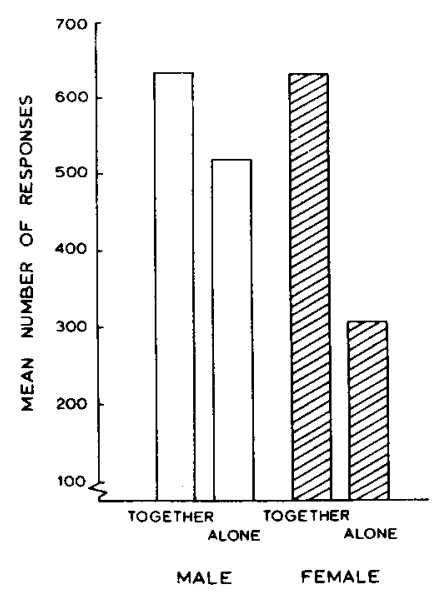

Fig. 1. Mean total number of responses as a function of sex and coaction. 


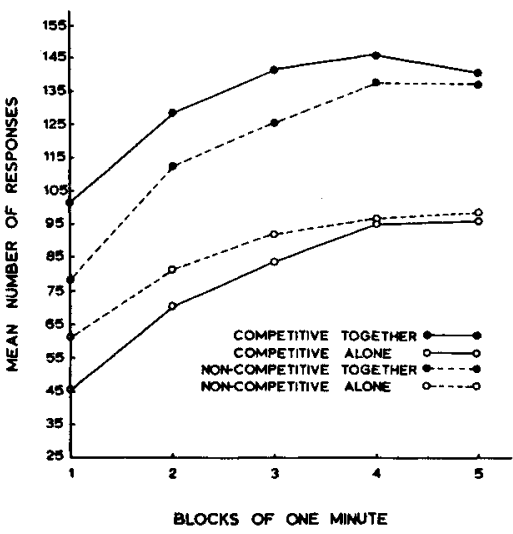

Fig. 2. Mean number of responses each minute as a function of competition and coaction.

respond differently from females when alone and when together. This interaction is illustrated in Fig. 1. It can be seen that the output of females is about the same as that of males when a coactor is present. Solitary male performance is only slightly below that of coacting males, whereas solitary female performance is considerably less than that of coacting females.

Within Ss, there is an overall increase in responding as the session proceeds $(F=56.42$, df $=4 / 288, p<.001)$ and a significant Time by Sex interaction $(F=16.45, \mathrm{df}=4 / 288, \mathrm{p}<.001)$, since the rate of increase is less for females than for males. In addition, there is a significant interaction between time, competition, and coaction $(F=2.72, \mathrm{df}=4 / 288, \mathrm{p}<.05)$. These trends are plotted in Fig. 2.

Coacting Ss who also are competitively motivated make more responses than coacting noncompetitive Ss until the last $2 \mathrm{~min}$ of the session. When Ss are alone, competition has little effect and may, in fact, depress performance slightly.

\section{DISCUSSION}

These results demonstrate that the males "work hard" both alone and in the presence of a coactor, whereas the output of the females is quite low when alone. However, the presence of a coactor raises the performance of the females to the same level as that of the males. On this basis, the effort demanded by the task can be ruled out as a contributor to low female performance, thus supporting the initial proposal that females are more sensitive than males to the social situation.

There is no indication from the data that females are less competitive than males. In the coacting situation, the competitive instructions serve to increase the rate of responding of both sexes, but the same instructions have little effect when the Ss are alone. This suggests that some form of evaluation or comparison of results is necessary to make the competitive instructions effective. It also is clear that if competition is required for coaction effects to occur, it need not be intense.

\section{REFERENCES}

ALLPORT, F. H. Social psychology. Boston: Houghton Mifflin, 1924.

CHURCH, R. M. The effects of competition on reaction time and palmar skin conductance. Journal of Abnormal \& Social Psychology, $1962,65,32-40$.

CHURCH, R. M., MILLWARD, R. B., \& MILLER, P. Prediction of success in a competitive reaction time situation. Journal of Abnormal \& Social Psychology, 1963, 67, 234240.

COTTRELL, N. B. Performance in the presence of other human beings: Mere presence, audience, and affiliation effects. In $E$. C. Simmel, R. A. Hoppe, and G. A. Milton (Eds.),
Social facilitation and imitative behavior. Boston, 1968. Pp. 91-110.

CROWNE, D. P., \& MARLOWE, O. The approval motive: Studies in evaluative dependence. New York: Wiley, 1964.

DASHIELL, J. G. Experimental studies of the influence of social situations on the behavior of individual human adults. In C. Murchison (Ed.), Handbook of social psychology. Worcester: Clark University Press, 1935.

UESUGI, T. K., \& VINACKE, W. E. Strategy in a feminine game. Sociometry, 1963, 26, 75-88.

ZAJONC, R. B. Social facilitation. Science, 1965 , $149,269-274$

ZAJONC, R. B. Social psychology: An experimental approach. Belmont, Calif: Wadsworth, 1966.

\section{NOTE}

1. This research was supported by Grant No. PA0332 from the National Research Council of Canada and a grant from the Department of Labour, Government of Canada.

\section{Knowledge of intraword redundancy by beginning readers}

DEBORAH LOTT, Harvard University, Cambridge, Mass. 02138, and FRANK SMITH, Ontario Institute for Studies in Education, Toronto, Ontario, Canada

Development of the ability to make use of sequential redundancy within visually presented words was measured by the difference between recognition threshold for letters in words and letters presented individually for 90 Ss 120 each from Grades 1 through 4 and 10 adults). Results indicate that implicit knowledge of sequential redundancy in familiar three-letter words can be apparent even in Grade-1 readers and increases slightly up to Grade 4, when approximately adult skill may be achieved.

Adult readers are able to predict successive letters of words with far better than chance accuracy (Garner, 1962, Chap. 7,8 ), and can identify letters in words on less visual information than they require to identify the same letters in nonwords (Smith, 1969). This ability to make use of sequential redundancy, or sequential constraints, within words must be based on an acquired implicit knowledge of word structure. In the study to be reported, the development of this knowledge of sequential redundancy was examined in beginning readers.

An earlier unpublished study by the present authors indicated that beginning readers quickly acquire a useful knowledge of sequential redundancy. In a comparison of letter identifications in words and nonwords, third graders made significantly more use of the redundancy in words than did first graders. However, fifth graders failed to show any improvement over the third graders, suggesting that a ceiling may be reached with simple material very quickly. The purpose of the present study was to examine more closely how children develop adult-level skills in the use of sequential redundancy in the recognition of familiar three-letter words.

The technique of both the unpublished study and the study to be reported here is to project a stimulus word or letter at below contrast threshold and to gradually increase contrast intensity. The relative intensity of the stimulus when a letter is correctly identified is taken to be an indicator of the amount of stimulus information required to make that identification. The average difference for 